\title{
Analysis of Physical States of Water in Soybean Seeds by NMR
}

\author{
Nobuaki Ishida, Hiromi Kano, ${ }^{*}$ Toshio KoBayashI \\ and Takashi YoshiDA** \\ National Food Research Institute, Kannondai, \\ Tsukuba Science City, Ibaraki 305, Japan \\ * National Institute of Agrobiological Resources, Kannondai, \\ Tsukuba Science City, Ibaraki 305, Japan \\ **Shikoku National Agricultural Experiment Station, \\ Zentsuji, Kagawa 765, Japan \\ Received May 12, 1988
}

\begin{abstract}
The physical characteristics of water in soybean seeds were investigated in relation to the water content, respiratory activity, and the imbibitional damage during germination. Imbibitional damage was severe at water contents below $10 \%$ where only the strongly bound water existed while it did not appear over $20 \%$ where free water existed and the membranes of cells had already recovered their functions. Taking the changes of ${ }^{1} \mathrm{H}-\mathrm{NMR}$ signals with water contents into account, the water absorbed in humid air was considered to be concentrated in a certain place in soybean seeds while the water absorbed by soaking was restricted by stored materials. The respiratory activity of seeds which absorbed water from humid air rose according to the increase of water content with a tendency similar to the free water.
\end{abstract}

It was reported that the extent of imbibitional damage decreased with increasing initial water contents of soybean seeds at germination. ${ }^{1 \sim 4)}$ The damage began to decrease at the initial water content over $10 \%$, where a ${ }^{31} \mathrm{P}-\mathrm{NMR}$ signal in cytoplasm was first detected, and was no longer observed above $20 \%$, where the function of vacuoles was anticipated from the ${ }^{13} \mathrm{C}$-NMR signal. ${ }^{5}$ Between these two levels of water contents, 10 and $20 \%$, the amount of leachate from seeds by soaking in water decreased with increasing initial water contents and became almost negligible above $20 \%{ }^{1)}$

These facts mean that the physical states of water in seeds at the initiation of imbibition in the stage of germination have a close relationship to the imbibitional effect and the release of stored materials. In this paper we have investigated the characteristics of water in soybean seeds in relation to the mechanism of imbibitional damage, which was deduced by another experiment concerning mechanical destruction of seed structure by rapid water absorption. ${ }^{1)}$

\section{MATERIALS AND METHODS}

Soybean seeds. Soybeans (Glycine max cv. Enrei) were cultivated in the field from June to October by the conventional method described previously. ${ }^{5}$

Water sorption isotherm. To control the water content, soybean seeds from which the coats were peeled were placed in a desiccator with saturated salt (commercial special grade) solution, the relative humidity of which was known. ${ }^{6)}$ Then, the desiccator was left at 25 or $5^{\circ} \mathrm{C}$ for one week to reach an equilibrium of water content to its relative humidity.

NMR measurements. All NMR measurements were done with an external lock $\left({ }^{2} \mathrm{D}\right)$ by a JEOL FX-100 spectrometer. The diameter of the sample tube was $10 \mathrm{~mm}$ and a soybean was placed in it without any treatment. The spin-lattice relaxation times were measured by the inversion recovery method $\left(180^{\circ}-\tau-90^{\circ}\right.$ pulse sequence) and spin-spin relaxation times were by the Carr-PurcellMeiboom-Gill method $\left(90^{\circ}-\tau-180^{\circ}\right.$ pulse sequence).

Respiration measurements. Endogenous oxygen uptake was traced in a closed chamber by an oxygen electrode at $25^{\circ} \mathrm{C}$. 


\section{RESULTS}

Figure 1 shows the relationship between the respiratory activity and the water content in soybeans. The respiratory activity which was observed as oxygen uptake increased gradually from the water content from $10 \%$ to $20 \%$, and sharply over $20 \% \%^{77}$

A sorption isotherm of dehulled soybean seeds is shown in Fig. 2. It appeared sigmoidal, the result of which was almost the same as that for soybean embryos reported by Vertucci et al. ${ }^{7)}$ Using sorption isotherm curves (Fig. 2),

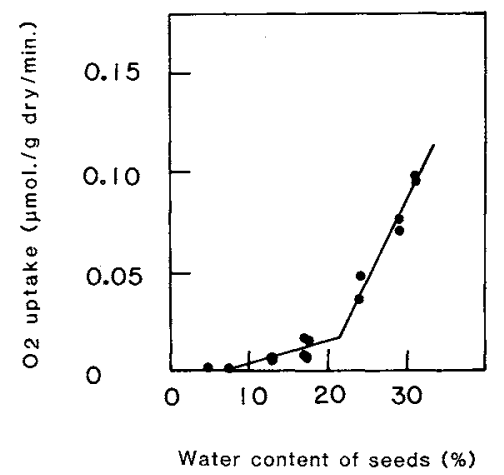

FIG. 1. Respiration Rate of Soybean Seeds with Various Water Contents.

Peeled soybean seeds were incubated in humiditycontroled air at $5^{\circ} \mathrm{C}$.

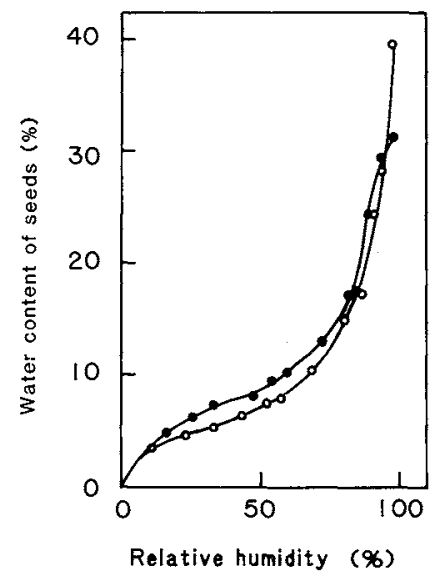

FIG. 2. Water Sorption Isotherm Curves of Soybean Seeds.

Peeled soybean seeds were placed in desiccators with known relative humidities at $5^{\circ} \mathrm{C}(\mathrm{O})$ and $25^{\circ} \mathrm{C}(\mathrm{O})$. thermodynamic parameters, i.e., differential enthalpy $(\Delta H)$, free energy $(\Delta G)$, and differential entropy $(\Delta S)$, were calculated. ${ }^{8)}$ Thermodynamic parameters derived from Fig. 2 were plotted against the water content as shown in Fig. 3. The parameters were given by the following equations,

$$
\begin{aligned}
& \Delta H=R T_{1} T_{2} /\left(T_{2}-T_{1}\right) \times \ln \left(A w_{1} / A w_{2}\right) \\
& \Delta G=R T \ln (A w) \\
& \Delta S=(\Delta H-\Delta G) / T
\end{aligned}
$$

where $A w_{1}$ and $A w_{2}$ are the relative humidities at two different temperatures at a given tissue water content. Differential enthalpy $(\Delta H)$, the heat of sorption at a given temperature range being measured, rises to a peak at the water content of 6 to $7 \%$ due to the increase of the affinity among adjacent water molecules when the surfaces of dry materials are almost covered with water molecules. ${ }^{8)}$ Therefore the peak of $\Delta H$ indicates the end point of monolayer absorption of water. The differential enthalpy of less negative values below 0 at the water content above $7 \%$ indicates a second region of water bound with much less affinity,

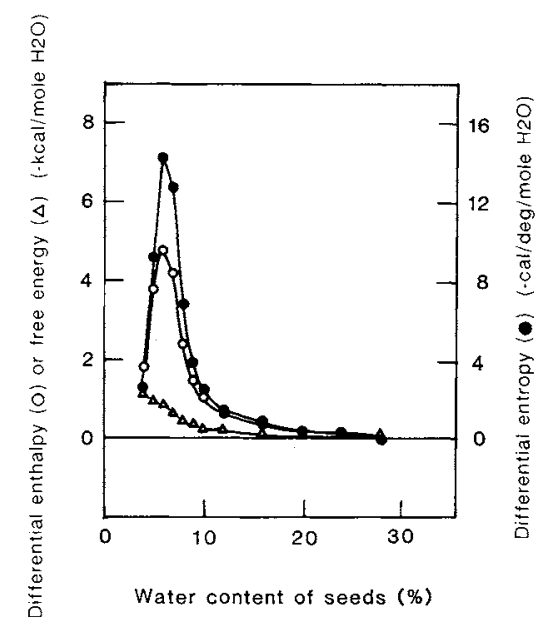

FIG. 3. Changes of Differential Enthalpies, Differential Entropies, and Free Energies in Water Sorption of Soybean Seeds.

Differential enthalpy $(\Delta H: O)$, differential entropy $(\Delta S$ : -), and free energy $(\Delta G: \triangle)$ were calculated using the sorption isotherm curves at $5^{\circ} \mathrm{C}$ and $25^{\circ} \mathrm{C}$ by the method of Schneider. $^{81}$ 
i.e, loosely bound water. It declined almost to zero at the water content more than $20 \%$, involving the appearance of bulk free water. ${ }^{7.9)}$

The differential free energy $(\Delta G)$, which depends on the relative humidity indicates the activity to transfer additional water molecules from the vapor state to the absorbing surface. It decreased with increasing water content.

The differential entropy $(\Delta S)$ which was derived from $\Delta H$ and $\Delta G$ shows the trends of differential enthalpy change. The large differential negative entropy involves the relatively nonrandom state of water on the surface of hygroscopic materials. ${ }^{8,9)}$

The amount of NMR detectable water (free water) of seeds in relation to the water content is shown in Fig. 4. Soybean seeds of the initial water content approximately $7 \%$ were allowed to imbibe water either by keeping them in air of various humidities or by soaking in water. Open circles $(O)$ show the results when seeds absorbed water from humid air and open triangles $(\triangle)$ when seeds were soaked in water. In other words the former shows slow incorporation of water into seeds keeping their cell organizations and functions, and the latter is rapid absorption of water without biological

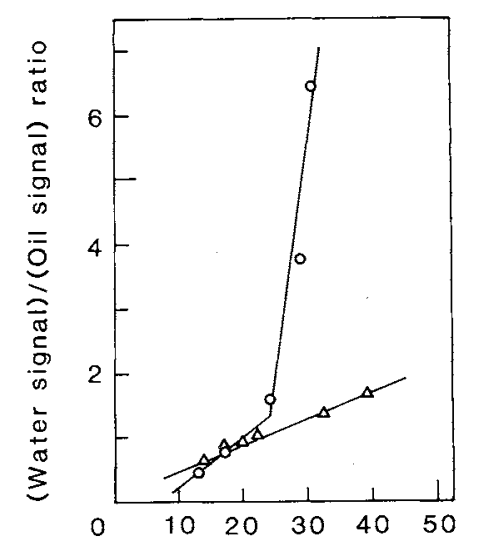

Water content of seeds (\%)

Fig. 4. Relationship between Free Water and Water Content of Soybean Seeds.

Water contents of soybean seeds were adjusted in humid air $(O)$ or in water $(\triangle)$. Free water contents were indicated as the ratio of the signal height of water to that of intrinsic oil in ${ }^{1} \mathrm{H}-\mathrm{NMR}$ of soybean seeds. controls.

In the case of absorption from humid air, the water signal showed a biphasic transition. It increased gradually up to $24.3 \%$ and increased more steeply over $24.3 \%{ }^{10}{ }^{10}$ Taking into account the quantitative relation between the increase of water content in seeds and the amount of free water observed, most of the water was restricted water at the water contents from 10.3 to $24.3 \%$ while above $24.3 \%$ free water showed a sharp increase. In the case of soaking in water, no steep increase of the water signal could be observed over all of the water content regions tested. This suggests that in the former case $(\bigcirc)$ water is concentrated in an certain place in the seeds and free water exists even at the relatively low water content. On the other hand, when a seed was soaked in water $(\triangle)$, the membranes of the seeds were broken, because sudden water intake swelled the constituents, and most of the water was absorbed into the crevices among molecules such as proteins ${ }^{11}$ and saccharides, and restricted.

Figure 5 shows the relationship between relaxation times of water protons and the water

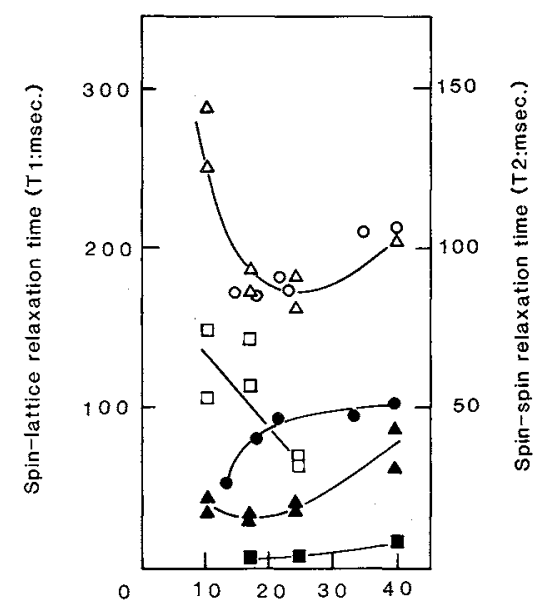

Water content of seeds (\%)

FIG. 5. Changes of Proton Relaxation Times of Water Protons in Soybean Seeds in Relation to Water Content. Changes of relaxation times of water protons of soybean seeds which were kept in humid air $\left(T_{1}: \mathbf{\Delta}, \triangle\right.$ and $T_{2}: \mathbf{\square}$, $\square)$ and soaked in water $\left(T_{1}: \mathbf{O}, O\right)$ are indicated. 
content of soybean seeds. Two pairs of $T_{1}$ 's were observed: $T_{1}(\mathbf{\Delta}$ and $\Delta$ ) for the seeds incubated in humid air and $T_{1}(\bigcirc$ and $\bigcirc)$ for those soaked in water. Both seeds kept in humid air and those soaked in water showed similar changes in the longer proton relaxation times $(\triangle, \bigcirc)$. They became long upon decreasing the water content below $20 \%$. This was assumed by the measurement of spin-spin relaxation time, $T_{2}(\square)$. With shorter spin-lattice relaxation times $(\boldsymbol{\Delta}, \boldsymbol{O})$, the tendency of the change was different between the seeds kept in humid air and those soaked in water. The former, which is considered to correspond to the relaxation time of the water in cytoplasm ${ }^{5}$ became longer with increasing water content in seeds above $17.1 \%$. It also became longer at the water content of $10.3 \%$. This may be ascribed to the characteristics of spin-lattice relaxation time in an extremely low water content region. ${ }^{12)}$ Considering that $T_{2}$ of this compartment ( $\mathbf{0}$ ) at $10.3 \%$ was too short to be measured, water may have lost its fast mobility because the concentration of soluble compounds became high, while the latter lengthened rapidly up to $100 \mathrm{~ms}$ from 10 to $20 \%$ and it no longer changed above $20 \%$. This indicates that the water with shorter relaxation time absorbed by soaking was a different kind from that absorbed from vapor which is considered to be active and to be in cytoplasm.

\section{DISCUSSION}

In the germination tests reported in our previous paper, ${ }^{1)}$ the ratio of normal germination was considerably less at the water content below $10 \%$ because of imbibitional effects. Imbibitional effects were no longer observed above $20 \%$. The two points of water content above mentioned, $10 \%$ and $20 \%$, almost corresponded to those of the peak and zero point of $\Delta \mathrm{H}$ in the thermodynamic parameter by the sorption isotherm curve (Fig. 3). In other words, the lower value was the end point of the monolayer absorption of water while the higher value was the starting point of the occupation of space with free water, which is interpreted as a localized solution effect. ${ }^{9}$ ) Those water contents correspond to the point of appearance of the free water signal and that of the rapid increase of water signal by NMR measurement (Fig. 4), respectively. Based on the finding on thermodynamic parameters, the free water in the seed at the water content approximately 10 to $20 \%$ was considered to be in a transitive condition like exchangeable water for monolayer-absorbed water or loosely bound water. ${ }^{13)}$ Within this region of hydration, there were great changes in the ability of the seed to withstand a rapid inflow of water. ${ }^{1)}$

The physical state of water in the soybean seeds absorbed from vapor which is attributed to cytoplasmic water both from the results of relaxation times (Fig. 5) and the findings during maturation of seeds, ${ }^{\text {) }}$ is considered to be different from that absorbed rapidly by soaking. In the former case, free water increased rapidly at the water content above $20 \%$, but in the latter case the increase of free water was slow over all of the water content regions tested (Fig. 4). When the dry seeds (initial water content is below $10 \%$ ) were soaked in water, most of the water incorporated is considered to be restricted, which is different from biologically active water because the relaxation time showed a different movement from that of cytoplasmic water (Fig. 5). Dry membrane in seeds are considered to be porous from the fact that leakage of solutes was fast at the first stage (within $5 \mathrm{~min}$ ) of imbibition. ${ }^{14.15}$ ) When seeds are soaked in water, water rapidly incorporated through the porous membrane is absorbed by the materials stored in the seed such as proteins and saccharides which swell suddenly upon hydration, resulting in the breakdown of the dry and inactive membrane organizations. On the other hand, in seeds kept in humid air, slow hydration of both membrane and stored materials without breaking down the organization of membrane, restores the biological function of membrane, which regulates further incorporation of water. ${ }^{10,16,17)}$ The same fact was observed in our previous paper, that the leakage of solutes 
from the seed with the initial water content of approximately $20 \%$ was small and breakdown of cotyledons upon soaking was not observed above this water content. ${ }^{1)}$ This is not a contradiction of the findings of Tilden and West ${ }^{18 \text { ) }}$ that the imbibitional effect was avoided by slowing the rate of hydration of soybean seeds which were sensitized and that their predisposition to imbibitional damage was diminished by priming biological processes in humid conditions before imbibition of water.

The biological activities like metabolism and enzymatic reactions are considered to turn into the activity of respiration. The rapid increase of respiration of seeds was observed at water contents above $20 \%$, and at water contents below $10 \%$, respiration almost ceased (Fig. 1). The changes of respiratory activity according to the increase of water content showed a similar tendency to that of free water (Fig. 4) which has a high mobility and a long relaxation time. Considering that the existence of free water is regulated by the function of membrane as discussed above, the respiratory activity indicates the extent of reorganization of the membrane in seeds, which has a close correlation with the imbibitional effect.

We concluded that the imbibitional effect in germination is caused by mechanical destruction of cell membranes in embryos and cotyledons because of rapid absorption of water by the stored materials and their consequent swelling. This effect is observed typically at initial water contents below $10 \%$ where all water in the seeds is restricted or bound, and no longer observed above $20 \%$ where there is free water in the seeds. Slow hydration of seeds up to approximately $20 \%$ restores the functions of the membranes such as selective permeability, which prevents the penetration of vast amounts of water to be absorbed by stored materials.

Acknowledgments. Authors thank Dr. S. Yamazaki of Tokyo University for his critical reading of the manuscript, discussion, and encouragement. We also thank Mrs. S. Sudo for assistance in cultivating and preparing soybeans, and Dr. K. Saio for her valuable advice.

\section{REFERENCES}

1) N. Ishida, H. Kano, T. Kobayashi, H. Hamaguchi and T. Yoshida, Agric. Biol. Chem., 52, 2771 (1988).

2) P. R. Hobbs and R. L. Obendorf, Crop Sci., 12, 304 (1972).

3) E. N. Ashworth and R. L. Obendorf, Agronomy J., 72, 923 (1980).

4) R. L. Obendorf and P. R. Hobbs, Crop Sci., 10, 563 (1970).

5) N. Ishida, H. Kano, T. Kobayashi, H. Hamaguchi and T. Yoshida, Agric. Biol. Chem., 51, 301 (1987).

6) L. B. Lockland, Anal. Chem., 32, 1375 (1960).

7) C. W. Vertucci and A. C. Leopold, Plant Physiol., 75, 114 (1984).

8) M. J. Schneider and A. S. Schneider, J. Membrane Biol., 9, 127 (1972).

9) L. B. Lockland, Food Technol, 23, 1241 (1969).

10) V. Seewaldt, D. A. Priestley, A. C. Leopold, G. W. Feigenson and F. Goodsaid-Zalduondo, Planta, 152, 19 (1981).

11) H. B. Bull, J. Amer. Chem. Soc., 66, 1499 (1944).

12) T. C. Farrar and E. D. Becker, "Pulse and Fourier Transform NMR," Academic Press, New York, 1971, pp. $46 \sim 65$.

13) P. S. Yang and J. A. Rupley, Biochem., 18, 2654 (1979).

14) W. J. Bramlage, A. C. Leopold and D. J. Parrish, Plant Physiol., 61, 525 (1978).

15) E. W. Simon and H. H. Wiebe, New Phytol., 74, 407 (1975).

16) E. W. Simon, New Phytol., 73, 377 (1974).

17) D. J. Parrish and A. C. Leopold, Plant Physiol., 59, 1111 (1977).

18) R. L. Tiden and S. H. West, Plant Physiol., 77, 584 (1985). 